\title{
Entre dioses y hombres: para una interpretación del problema de lo divino y lo sagrado en el pensamiento de Martin Heidegger
}

\section{Between gods and men: towards an interpretation of the problem of the divine and the holy in Martin Heidegger's thought}

\author{
Paloma MARTÍNEZ MATÍAS \\ Universidad Complutense de Madrid
}

Recibido: 01-07-2013

Aceptado: 19-11-2013

\section{Resumen}

En confrontación con las interpretaciones que asignan un significado religioso o teológico a las referencias a los dioses, a lo sagrado, o al "último dios" presentes en la obra de Martin Heidegger, este trabajo defiende una lectura en clave estrictamente ontológica de tales referencias. Para ello, se remite al diálogo que Heidegger mantiene con la poesía de Hölderlin y se argumenta que el significado que atribuye a la invocación hölderliniana a los "dioses huidos" depende del carácter ontológico que, en otro contexto, concede a la nominación de los dioses característica del decir poético griego. Ese mismo carácter se pone de manifiesto en el sentido que, según Heidegger, ostenta la apelación a "lo sagrado" de la poesía de Hölderlin como nombre poético del ser en su despliegue histórico. Finalmente, dicha interpretación se hace extensiva a la figura del "último dios", resaltando que su comprensión pasa por atender a la exégesis heideggeriana de la cuestión de la huida de los dioses en la obra poética de Hölderlin.

Palabras clave: metafísica, ontología, Hölderlin, poesía, Grecia, mitología, teología.

\begin{abstract}
In contrast to interpretations that assign a religious or theological meaning to references to the gods, the holy or the "last god" in Martin Heidegger's work, this study defends a strictly ontological reading of these references. In so doing, it refers to Heidegger's dialogue with Hölderlin's poetry and argues that the meaning given by the philosopher to
\end{abstract}


Hölderlin's invocation of the "fugitive gods" depends on the ontological character he attributes in another context to the nomination of the gods characteristic of Greek poetical saying. The same character may be inferred from Heidegger's construction of the meaning of the appeal to "the holy" in Hölderlin's poetry as the poetical name of the being as historically deployed. Finally, this interpretation extends to the figure of the "last god", noting that in order to understand it, regard must be had to Heidegger's exegesis of the question of the flight of the gods in Hölderlin's poetic works.

Keywords: metaphysics, ontology, Hölderlin, poetry, Greece, mythology, theology.

\section{El problema de lo divino en Heidegger}

Entre los diferentes desafíos hermenéuticos a los que se enfrenta todo lector de la obra de Martin Heidegger, destaca sin duda el que se abre con la pregunta por el sentido de las referencias a los dioses, lo sagrado, los celestes o los inmortales que comienzan a aparecer en ella a mediados de los años treinta. De entrada, una notable oscuridad envuelve ese decir sobre los dioses o lo sagrado: salvo contadas excepciones, en su comparecencia errática pero en absoluto marginal se acusa la ausencia de aclaraciones precisas o relativamente elaboradas que permitieran arrojar luz sobre su significado, a la vez que ofrecieran las claves para interpretar su lugar y relevancia dentro del horizonte de la singular reapertura de la cuestión del ser que acometen los textos heideggerianos. A esta dificultad se suma la que proviene de la naturaleza notoriamente ambigua, críptica o incluso contradictoria de las manifestaciones efectuadas por Heidegger a lo largo de su dilatada andadura sobre la relación entre su pensamiento y la cuestión teológica.

Tanto en los inicios de su trayectoria como en momentos posteriores, Heidegger insiste en el ateísmo que debe asumir la posición filosófica1: la forma de existencia que supone la fe constituye el "enemigo mortal" de la subyacente a la filosofía 2 , ya que la fe se caracteriza por haber dado de antemano respuesta a aquellos interrogantes cuya radicalidad forja la especificidad del cuestionar filosófico - el ejemplo paradigmático se hallaría en la pregunta: ¿por qué es el ente y no más bien la nada?-, restringiendo con ello la viabilidad de su formulación al "como si..." de la mera simulación 3 . La diferencia abisal que, según Heidegger, existe entre la incondicionalidad de la fe y el carácter problemático del pensamiento 4 dibuja una línea abruptamente fronteriza no sólo entre la filosofía y la creencia religiosa, sino

\footnotetext{
1 Cfr. Heidegger, M., Phänomenologische Interpretationen zu Aristoteles. Einführung in die phänomenologische Forschung, Frankfurt am Main, Vittorio Klostermann, 1994, pp. 197 y 199.

2 Cfr. Heidegger, M., «Phänomenologie und Theologie», en Wegmarken, Frankfurt am Main, Vittorio Klostermann, 2004, p. 66.

3 Cfr. Heidegger, M., Einführung in die Metaphysik, Tübingen, Niemeyer, 1998, p. 5. Por ello, Heidegger afirma en este curso de 1935, con idéntica expresión a la utilizada en la conferencia de 1927 «Phänomenologie und Theology» (en Wegmarken, op. cit., p. 66), que una "filosofía cristiana" sería algo así como un "círculo cuadrado" (en alemán, ein hölzernes Eisen), esto es, un completo contrasentido.
}

4 Cfr. Heidegger, M., Was heißt Denken?, Tübingen, Niemeyer, 1997, p. 110. 
también entre la filosofía y la teología, en la medida en que el fundamento legítimo del conocimiento teológico se circunscribe y limita al marco de la fe ${ }^{5}$. De tal separación parecería derivarse sin vacilación alguna la imposibilidad de dilucidar el sentido de la mencionada constelación de nociones relativas a la esfera de lo divino desde una perspectiva tanto religiosa como teológica.

Sin embargo, los orígenes católicos de Heidegger, la sólida formación teológica que recibe en su juventud, el interés por la escolástica de sus primeros escritos académicos y la reflexión que emprende en la etapa más temprana de su carrera docente sobre la experiencia vital de las comunidades cristianas primitivas y la mística medieval, han situado recurrentemente su obra bajo la sospecha de una influencia religiosa de alcance decididamente mayor que la admitida por su autor y de inexcusable reconocimiento para su adecuada inteligibilidad. Así, en la interpretación que percibe en la analítica existenciaria de Ser y tiempo un intento de formalizar las estructuras de la vida fáctica cristiana -doblemente inspirado por las críticas de Lutero a la teología medieval y de Kierkegaard a la teología especulativa de Hegel- se ha localizado el motivo de la entusiasta acogida que tuviera este texto en círculos de teólogos protestantes y católicos6. También el cambio de perspectiva o "giro" (Kehre) que, a partir de los años treinta, impulsa al pensamiento heideggeriano a trasladar su foco de atención desde el Dasein o ente que somos al ser con el fin de interrogar por su verdad y por el devenir histórico que la revela fue objeto de una intensa recepción por parte de la teología hermenéutica, principalmente a raíz de la publicación de la "Carta sobre el humanismo". Y a la obra más tardía de Heidegger no han dejado de imputarse connotaciones "religiosas" o dimensiones "místicas"7 que probablemente se encontrarían a la base de la fenomenología "espiritualizada" surgida en torno a ella en el marco de la más reciente filosofía francesa ${ }^{8}$.

Tales lecturas no han obviado el desmontaje que, en el seno de su confrontación con la metafísica, Heidegger llevara a cabo de la teología a consecuencia de la constitución ontoteo-lógica que detecta en aquélla9. Recordemos que con el término "metafísica" Heidegger designa cierto acontecimiento unitario que determinaría en su conjunto la historia de Occidente y aún vigente en nuestra propia actualidad histórica: el que se emplaza en el encubrimiento, sepultamiento u olvido de la diferencia entre el ente y su ser, entendida como

\footnotetext{
5 Cfr. Heidegger, M., «Phänomenologie und Theologie», en Wegmarken, op. cit., p. 61.

${ }^{6}$ Cfr. Caputo, J. D., «Heidegger and Theology», en Guignon, C., The Cambridge Companion to Heidegger, Cambridge University Press, 1993, pp. 272-75. En la recepción teológica de Ser y tiempo ocupa un lugar eminente, en los años inmediatamente posteriores a su publicación, el teólogo protestante Rudolf Bultman, y más tarde el teólogo católico Karl Rahner. Sobre esta cuestión, cfr. Jung, M., «Heidegger und die Theologie. Konstellationen zwischen Vereinnahmung und Distanz», en Thomä, D., Heidegger Handbuch, Stuttgart, Metzer, 2003, pp. 476-79.

7 Cfr. Caputo, J. D., «Heidegger and Theology», op. cit., pp. 282-83.

8 Cfr. Jung, M., «Heidegger und die Theologie. Konstellationen zwischen Vereinnahmung und Distanz», op. cit., pp. 479-80.

${ }^{9}$ Aun cuando la reflexión sobre la intrínseca vinculación entre la metafísica y la teología comienza ya en la obra temprana de Heidegger, el sentido de la expresión "onto-teo-logía" es tematizado en la conferencia de 1957 «Die onto-theo-logische Verfassung der Metaphysik» (en Identidad y diferencia/Identität und Differenz, Barcelona, Anthropos, 1988).
} 
diferencia entre las cosas que hay o aparecen y aquello en lo que ese haber o aparecer consiste. Si en ese encubrimiento resulta crucial la identificación platónica del ser con la idea, el postulado de una idea de todas las ideas, concebida como causa de la permanencia y manifestación de todo ente, implica para Heidegger la introducción de una causa suprema y primera que tanto en Platón como en Aristóteles recibe el nombre de tò theîon, lo divino. De esta forma, la interpretación del ser como idea origina la conversión del mismo en ente que inaugura la metafísica, al tiempo que su asimilación al dios transforma a ésta en teología 10 . La crítica heideggeriana a la metafísica exige, por tanto, una puesta en cuestión de la teología inherente a ella que engloba el rechazo de la representación de la divinidad que la sustenta: en el dios que la filosofía describió como fundamento último del ser, ente supremo y creador, Causa sui y causa de todo ser-causa, máximo valor y garantía de toda validez, se evidencia, a su juicio, más que el producto del olvido metafísico del ser, uno de los principales vehículos de su acaecer histórico ${ }^{11}$.

Pero este mismo cuestionamiento conducirá a Heidegger a advertir que, si bien su pensamiento se ubica fuera de toda teología, no "se ha decidido en absoluto por el ateísmo»" 12 , de suerte que se incurriría en error de hacerse equivaler su comprensión de la esencia del ser humano a partir de su exposición al ser -su definición como Dasein en tanto abertura o "ahí" $(D a)$ para la presencia de todo lo que es- con un posicionamiento ateo ${ }^{13}$. En contradicción con lo expuesto anteriormente, la reflexión heideggeriana se desvincula ahora del ateísmo precisamente en función de su crítica a la teología: por asentarse sobre la premisa incuestionada del dios de la filosofía, la afirmación teísta y la negación atea de su existencia compondrían las dos ramas de una disyuntiva que opera dentro de la propia lógica implantada por la metafísica en su constitución onto-teo-lógica. Decantarse por una u otra significaría entonces permanecer preso del paradigma sobre cuyo distanciamiento quiere construirse el pensamiento heideggeriano ${ }^{14}$.

En esta recusación más tardía del ateísmo se ha divisado la brecha que permitiría contemplar las alusiones al ámbito de lo divino presentes en su obra al modo de una propuesta de un nuevo concepto de dios. Pues, de acuerdo con tal recusación, Heidegger llegará a declarar que el "pensar sin dios" (gottloses Denken) que contrapone a la metafísica, obligado en tal contraposición a abandonar al dios de la filosofía, se hallaría «tal vez más cerca del dios divino (göttliches Gott)»15. Si expresiones como ésta sugieren la vindicación de un con-

10 Cfr. Heidegger, M., «Platons Lehre von der Wahrheit», en Wegmarken, op. cit., pp. 235-36. A este respecto Heidegger aclara que por teología entiende aquí «la interpretación de la "causa originaria" del ente como dios, y el relegamiento del ser al papel de esa causa que contiene en sí misma al ser y lo origina desde sí por tratarse de lo más ente del ente» (p. 236). La teología consistiría, por tanto, en la asimilación del ser al ente supremo - con el consecuente encubrimiento de la diferencia entre ente y ser- $\mathrm{y}$ en su erección en causa de la presencia o ser de todo otro ente.

11 Cfr. Heidegger, M., Beiträge zur Philosophie. Vom Ereignis, Frankfurt am Main, Vittorio Klostermann, 1994, p. 243.

12 Heidegger, M., «Brief über den Humanismus», en Wegmarken, op. cit., p. 352.

13 Cfr. ibid., pp. 350-51.

14 Cfr. ibid., p. 352. Cfr. igualmente Thurnher, R., «Gott und Ereignis - Heideggers Gegenparadigma zu Onto-Theologie», Heidegger Studien, 8, 1992, p. 98.

15 Heidegger, M., Identidad y diferencia/Identität und Differenz, op. cit., pp. 152-53. 
cepto positivo de dios más allá de su imagen tradicional y encaminado a superarla, tal hipótesis exegética ha creído verse confirmada a raíz de la esperada publicación de la serie de manuscritos inéditos redactados por Heidegger a partir de la segunda mitad de los años treinta. Como es sabido, el primero de estos escritos, titulado Beiträge zur Philosophie (Vom Ereignis), ostenta una compleja arquitectura articulada en seis "fugas" o "junturas" (Fugen), la última de las cuales gira en torno a la figura del "último dios" (letzte Gott), para algunos intérpretes el verdadero hilo conductor de este texto que dirige el diseño de las cinco fugas precedentes ${ }^{16}$. A pesar de que el discurso sobre el "último dios" se limita al puntual contexto de los escritos privados de Heidegger y, como si de una tentativa fallida se tratara, no vuelve a hacer acto de presencia en etapas ulteriores de su singladura, su inserción en la que fuera anunciada como su "segunda obra capital" 17 y el carácter concluyente que en ella se le otorga han sido interpretados como prueba de la esencial referencia a la cuestión de dios que anidaría en el núcleo más íntimo de su pensamiento18. Es, además, en este marco donde la tarea de la filosofía se cifra en un "pensar de la historia del ser" (seinsgeschichtliches Denken) que aspira a preparar el tránsito desde el "primer inicio" -nombre en esta obra para la metafísica- hacia lo que allí se denomina el "otro inicio". La ambivalencia hermenéutica que a menudo se acusa en los textos heideggerianos, exacerbada en este caso por el singular lenguaje ensayado en los Beiträge para alejarse de la terminología ontológica heredada, han propiciado la identificación de ese "otro inicio" con el anuncio de una época venidera de contenido distinto a la presente. En paralelo con tal versión del tránsito, a la parte de los Beiträge dedicada al "último dios" se ha atribuido el propósito de elaborar una suerte de teología postmetafísica y postcristiana destinada a suplantar a la teología tradicional. Descrito en su encabezamiento como «uno totalmente diferente frente a los que han sido, especialmente frente al cristiano» 19 , el "último dios" encarnaría la idea de la divinidad perteneciente a esa nueva teología, en cuyo terreno - y a tenor de la conocida familiaridad de Heidegger con la teología negativa- no podría recibir caracterización positiva alguna ${ }^{20}$.

No obstante, de una mirada a nuestro juicio más atenta no sólo a los escritos de este período, sino al legado heideggeriano en su conjunto y a la complejidad que en él entraña la noción de "superación" (Verwindung) en su aplicación a la metafísica, se desprende una visión por completo distinta de lo planteado en los Beiträge: lejos de apuntar al adveni-

16 Cfr. Kienzler, K., «"Der kommende Gott” - Die Elegie "Brot und Wein” bei Hölderlin», Archivio di Filosofia, 62/3, 1994, p. 305.

17 Cfr. Hermann, F.-W., Wege ins Ereignis. Zu Heideggers "Beiträge zur Philosophie”, Frankfurt am Main, Vittorio Klostermann, 1994, p. 6. Para una lectura crítica de esta visión de los Beiträge zur Philosophie, cfr. Martínez Marzoa, F., «A propósito de los "Beiträge zur Philosophie" de Heidegger», Daimon, 2, 1990, pp. 241-42.

18 Cfr. Thurnher, R., «Gott und Ereignis - Heideggers Gegenparadigma zu Onto-Theologie», op. cit., p. 81.

19 Heidegger, M., Beiträge zur Philosophie. Vom Ereignis, op. cit., p. 403.

20 Así, a partir de su lectura de los Beiträge, J.-F. Courtine se ha pronunciado a favor de esta "teología post-metafísica" proyectada en torno a la figura del último dios. En ella, este dios postmetafísico sólo habría recibido por parte de Heidegger determinaciones deliberadamente negativas para anunciarse como «un dios desconocido y esencialmente anónimo, ajeno en todo caso a toda iglesia instituida» («Les traces et le passage du Dieu dans les Beiträge zur Philosophie de Martin Heidegger», Archivio di Filosofia, 62/3, 1994, p. 531). 
miento de un nuevo período histórico, ese "otro inicio" consistiría en el ejercicio de reconocimiento y apropiación de la metafísica que daría a ver en ella el acontecimiento vertebrador de la historia de Occidente y el horizonte irrebasable en el que nos encontramos instalados 21 . En consecuencia, la única novedad del "otro inicio" estribaría en la toma de distancia frente a la metafísica que habilita su consumación o acabamiento -diagnosticado en este texto a partir de ciertos fenómenos asociados al creciente dominio de la técnica- y que por primera vez hace posible pensarla y abarcarla en su constitución unitaria como un todo ya clausurado, aunque no concluido en el tiempo ni mucho menos pretérito. La pretensión del proyecto filosófico heideggeriano radicaría así en la institución y establecimiento de esa distancia que a la vez demanda la asunción de nuestra estricta interioridad y pertenencia a la metafísica. Pero si se admite que no hay en la reflexión heideggeriana voluntad alguna de fundar un "nuevo presente" que relegara a la metafísica a la condición de un pasado cancelado o superado, también resulta de todo punto cuestionable que su discurso sobre el "último dios", al igual que las referencias a los dioses o a lo sagrado que recorren su obra, se concibieran con la finalidad de instaurar una "nueva teología" en sustitución de la anterior.

Descartar tal hipótesis hermenéutica pasa, a nuestro parecer, por examinar esta problemática a la luz del contexto que suscita y justifica el decir de Heidegger sobre los dioses: el diálogo que, tras su fracaso en el rectorado y hasta el final de sus días, mantiene con la poesía de Hölderlin y el análisis que a partir de él emprende del decir poético en su estrecha relación con el pensar. En lo que sigue, este trabajo tendrá por objetivo profundizar en este contexto como camino ineludible para dilucidar el significado del tema de lo divino en la trayectoria heideggeriana.

\section{Los dioses y el decir poético}

La cuestión de los dioses adquiere una importancia decisiva en el primer curso que Heidegger imparte sobre la poesía de Hölderlin en el semestre de invierno de 1934/3522. La propia elección del poema que guía su desarrollo, titulado "Germania” (Germanien), explica su focalización sobre esta precisa cuestión: en sus versos iniciales Heidegger lee una renuncia del poeta a llamar a los antiguos dioses -asimilados sin titubeos a los dioses griegos- que reposa sobre la experiencia de su huida. A partir de otros poemas de Hölderlin, la relación del poeta con los dioses se inscribe en el núcleo mismo de la tarea poética al indicarse que si «la tormenta y el rayo son el lenguaje de los dioses», el poeta «debe soportar sin apartarse, recoger y poner este lenguaje en la existencia del pueblo» ${ }^{23}$. Pues, también siguiendo a Hölderlin, Heidegger presenta a los dioses como la instancia en virtud de la cual el ser humano se constituye en ámbito de aparición de todas las cosas: sólo porque «los dioses se dirigen a nosotros, nos sitúan bajo su reclamo, nos llevan al lenguaje» 24 , y ello inclu-

\footnotetext{
${ }^{21}$ Cfr. Leyte, A., Heidegger, Madrid, Alianza, 2005, p. 188 y ss.; asimismo, cfr. Martínez Marzoa, F., «A propósito de los "Beiträge zur Philosophie" de Heidegger», op. cit., pp. 243-44.

22 Heidegger, M., Hölderlins Hymnen "Germanien” und "Der Rhein”, Frankfurt am Main, Vittorio Klostermann, 1999.

23 Ibid., p. 31.

24 Ibid., p. 70.
} 
so allí donde se ausentan o faltan sus señas, habitamos de antemano en la posibilidad de decirlas que permite su comparecencia. De ahí que se comente que la huida de los antiguos dioses cantada por Hölderlin no implica la desaparición de toda relación con la divinidad. Antes bien, la renuncia del poeta a invocarlos, idéntica a la resolución a prescindir de ellos y a soportar el dolor de su falta, comporta para Heidegger una forma de cercanía y preservación de su divinidad perdida 25 .

A lo largo de este curso, el interés del filósofo por el poeta se legitima apelando a la necesidad de comprender la ausencia de los dioses poetizada en su obra para poder dar respuesta a la pregunta sobre quiénes somos en nuestra actualidad histórica ${ }^{26}$ : en ese decir poético en torno a la huida de los dioses, Heidegger reconoce el descubrimiento efectuado por Hölderlin -palmariamente expresado en la conocida carta a Böhlendorf del 4 de noviembre de 180127- de la rigurosa dependencia de nuestro propio tiempo con respecto a Grecia; dependencia que a la vez se traduce en una radical alteridad u oposición frente a ella que impide todo retorno o imitación de lo griego 28 . La relevancia de este descubrimiento procede de la dimensión ontológica que Heidegger subraya en él al anotar que la nueva relación con los dioses fundada por la poesía de Hölderlin, coincidente con el resguardo de su divinidad ausente, posee la virtualidad de franquear el acceso «al ente en su totalidad de otra manera y de un modo esencial» 29 . Ello se debe a que -según se formula en la conferencia de 1936 "Hölderlin y la esencia de la poesía", que recoge algunas de las ideas centrales del curso de 1934/35- si el poetizar es un «originario nombrar a los dioses» ${ }^{30}$, también es, en la misma medida, un «nombrar fundacional del ser y de la esencia de todas las $\operatorname{cosas} »^{31}$ que en el inicio de la historia de Occidente fue llevado a cabo por Homero ${ }^{32}$ y en nuestro tiempo se habría realizado en la palabra de Hölderlin. Se constata así cómo en razón de su íntima conexión con la cuestión del ser en su vinculación al lenguaje y, muy especialmente, al decir poético, aquello a lo que los dioses remiten opera como índice de la distancia que simultáneamente nos une y separa de Grecia.

Por más que los diferentes cursos y conferencias sobre Hölderlin brinden ciertas claves para entender el sentido ontológico del decir sobre los dioses que Heidegger integra en su propio discurso a partir de la interpretación de su poesía, la clarificación explícita de esta problemática no se produce en el marco de tal interpretación, sino en la lección que, durante el semestre de invierno de 1942/43, pronuncia bajo el título de "Parménides y Heráclito" 33 . Al hilo de una reflexión sobre la naturaleza del mýthos, en ella se expone que

\footnotetext{
25 Cfr. ibid., pp. 95-97

26 Cfr. ibid., p. 77.

27 Cfr. Hölderlin, F., Ensayos, trad. de Martínez Marzoa, F., Madrid, Hiperión, 1990, pp. 125-28.

28 Cfr. Heidegger, M., Hölderlins Hymnen "Germanien" und "Der Rhein”, op. cit., pp. 291-96; Hölderlins Hymne “Andenken”, Frankfurt am Main, Vittorio Klostermann, 1992, pp. 68, 130-32 у 154; Hölderlins Hymne "Der Ister”, Frankfurt am Main, Vittorio Klostermann, 1993, pp. 168-70.

29 Heidegger, M., Hölderlins Hymnen "Germanien” und "Der Rhein”, op. cit., p. 82.

30 Heidegger, M., «Hölderlin und das Wesen der Dichtung», en Erläuterungen zu Hölderlins Dichtung, Frankfurt am Main, Vittorio Klostermann, 1996, p. 45.

31 Ibid., p. 43

32 Cfr. Heidegger, M., Hölderlins Hymnen “Germanien” und "Der Rhein”, op. cit., p. 184.

33 Cfr. Heidegger, M., Parmenides, Frankfurt am Main, Vittorio Klostermann, 1992.
} 
los dioses griegos afloran como la manifestación poética del ser, ya que a través de su nominación el ser emerge y cobra expresión en el ámbito del decir poético.

Antes de abordar este concreto asunto, es preciso señalar que eso a lo que Heidegger llama "ser" en su diferencia con respecto al ente alude a cierto trasfondo de abertura o entramado significativo -lo designado en Ser y tiempo con el concepto de "mundo"- que se oculta tras la presencia o aparición de cada cosa para hacer posible esa misma presencia. La diferencia entre lo ente y su ser reside, por tanto, en la distancia o hiato que media entre cada cosa que aparece y el sustraerse de esa dimensión inobjetivable, nunca presente y sólo manifiesta en su retracción que soporta su comparecencia. No obstante, debe advertirse de entrada -más tarde habrá de volverse sobre esta cuestión- que ser y ente no representan dos instancias que cupiera aislar o pensar separadamente: que el ente se muestre a costa del rehusarse del ser significa que no hay aparecer ni, por ende, "ser" de cosa alguna sin la retirada de ese trasfondo inaprehensible cuya única forma de exhibición consiste en la de su propio cierre y reserva. La confluencia que detecta en Grecia entre el lógos y el ser ${ }^{34}$ llevará a Heidegger a defender que ese mostrarse o haber de las cosas deviene estrictamente solidario de la operación de decirlas, hasta el punto de sentenciar que «sólo donde hay lenguaje impera un mundo» ${ }^{35}$. Pero así como el decir trivial encubre o deja pasar desapercibido su intrínseco ensamblaje con el venir-a-presencia del ente, el decir poético logra sacarlo a la luz por obra de su capacidad para poner de relieve el fondo de ocultación que impera en ese venir-a-presencia y tornarlo patente en su específico sustraerse.

Es por ello por lo que en el citado curso de 1942/43 Heidegger sostiene que, a partir de la experiencia del ser como alétheia -el salir de lo oculto que, sin embargo, queda anudado a una ocultación insuperable-, la singularidad del mýthos o relato poético griego radica en dar a ver el ser en su diferencia y a la vez indisoluble unidad con el ente por medio de la nominación de los dioses ${ }^{36}$. En términos de Heidegger: «La palabra como nominación del

34 Esta confluencia entre el lógos y el ser se afirma a la luz del sentido que cabe atribuir al légein griego más allá de su incuestionable referencia al decir y a partir de su aparición, fundamentalmente, en los fragmentos de Heráclito. En la medida en que en Grecia el légein designa tanto el decir o hablar como el reunir o juntar que al mismo tiempo separa y discierne, Heidegger lo identifica con el poner en una cierta articulación que hace posible el aparecer de las cosas: tal comparecencia lo es siempre de algo como algo, esto es, por medio de la articulación que supone la reunión de la cosa con las determinaciones que le son propias, al tiempo que su separación de las que no le convienen. Resulta evidente que esa articulación describe justamente aquello que tiene lugar en el decir. Pero Heidegger defenderá que, lejos de limitarse al dominio del lenguaje, el légein nombra en primera instancia el dejar aparecer o traer a presencia que acontece, también en virtud de tal articulación, en el mero trato o habérselas con las cosas característico de la existencia humana. De ahí que el lógos pueda referir en los textos de Heráclito al venir a presencia o salir a la luz al que alude asimismo el término phýsis en su común asimilación al ser. En función de ello, Heidegger plantea que es el remitir esencial del légein a ese comparecer de las cosas en el marco de la existencia humana lo que permite que signifique igualmente el decir o hablar. Esta circunstancia le conducirá a situar en ese mismo decir el ámbito de aparición de la totalidad del ente. Sobre esta cuestión, cfr., entre otros lugares, Heidegger, M., Einfürung in die Metaphysik, op. cit., p. 94 y ss., así como Heraklit, Frankfurt am Main, Vittorio Klostermann, 1994, p. 261 y ss.

35 Heidegger, M., Hölderlins Hymnen “Germanien” und "Der Rhein”, op. cit., p. 62.

36 Cfr. Heidegger, M. Parmenides, op. cit., p. 89. Para esta explicación del sentido de los dioses griegos, Heidegger menciona el libro de Otto, W. F., Los dioses de Grecia (trad. de Berge, R. y Murguía, 
ser, el mýthos, nombra el ser en su inicial ofrecerse a la vista y brillar - nombra tò theîon, es decir, los dioses» ${ }^{37}$. El erigirse de los dioses en plasmaciones del ser en su irreductibilidad frente al ente descansa sobre la correspondencia establecida en Grecia entre la mirada -théa-y la diosa -theá-38: los dioses son los que miran-theáontes- en y a través de todas las cosas, si bien ese mirar -theáo- se solapa en sí mismo con un mostrarse que habilita cualquier otro ver ${ }^{39}$. Así se comprende que los dioses, en su mirar, se ofrezcan a la vista y brillen en la familiaridad del ente. La mirada de los dioses se dirige en exclusiva al ser humano, que se distingue de cualquier otra cosa por acoger en su propia mirada, y en respuesta a ese mirar divino, el aparecer o la visión del dios ${ }^{40}$. En esta especial relación con el mirar de los dioses Heidegger sitúa el reflejo poético griego de la definitoria referencia al ser del hombre, que convierte su existencia en el espacio donde se abre la presencia de la totalidad del ente. Pero así como el hombre corriente sabe del ser sin reparar habitualmente en él, tampoco percibe a los dioses en su cotidiano ocuparse de las cosas: a pesar de que su patencia queda por entero ligada al ente, los dioses - al igual que los daímones- lo desbordan y exceden, y en este sentido personifican lo "extra-ordinario" (Un-geheures) que por todas partes circunda el ámbito de lo ordinario y en él se entrega pero en su particular sobrepasarlo 41 . Tal condición extra-ordinaria en contraposición a la trivialidad del ente obedece a que los dioses brillan en todas las cosas bajo el paradójico rostro de lo no-aparente ( $U n$ scheinbare) y nunca-presente, de lo que no se deja apresar y permanece indisponible por eludir toda voluntad de cálculo y planificación, de suerte que en ningún caso se confunden con el ente ni toleran derivación o explicación a partir de él12. De ese carácter no-aparente o no-presente de su singular presencia se deduce que los dioses se muestran ocultándose en el ente y sin que tal manifestación implique el abandono de su consustancial encubrimiento: lo que a través de los dioses comparece no es sino el hurtarse del fondo de abertura, oculto e inaprehensible en su ocultación, que sustenta en Grecia la presencia de las cosas. Por esta razón puede afirmarse que, a diferencia del decir trivial, la nominación de los dioses del decir poético griego pone de relieve el aparecer de un sustraerse que descubre el íntimo entrelazamiento de abertura y rehusamiento, de comparecencia y retracción que acaece en cada cosa que se exhibe.

\footnotetext{
A., Madrid, Siruela, 2003), publicado originalmente en 1929 y también citado en relación con esta misma cuestión en el primero de los cursos sobre Hölderlin. Y, en efecto, cabe pensar que la interpretación ontológica del sentido de los dioses griegos propuesta por Heidegger se apoyaría o estaría inspirada en este texto de Otto. Pues según se afirma en él, para el espíritu griego lo divino es «el fondo de todo lo que existe y sucede. Ese fondo se trasluce tan claramente en todas las cosas y acontecimientos que debe hablarse de él aun refiriéndose a los objetos más naturales y habituales» (p. 33). Sobre la cuestión de la relación entre los dioses y el decir poético, cfr., de este mismo texto, p. 197 y ss.

37 Ibid., p. 165.

38 Cfr. ibid., p. 160.

39 Cfr. ibid., p. 152 y ss.

40 Cfr. ibid., pp. 154 y 160.

41 Cfr. ibid., p. 161.

42 Cfr. ibid., pp. 150 y 156. Heidegger resalta en este punto la identificación en Grecia entre la esfera de los dioses y el ser al señalar que éste último constituye igualmente lo no-aparente y extra-ordinario que, pese a pertenecer de manera inmediata al ámbito de lo ordinario, nunca puede ser aclarado desde él (p. 150).
} 
Pero que Heidegger se refiera al "brillar" (scheinen) de la no-presencia de los dioses dentro de todo ente responde también a su descripción del mýthos como aquel decir cuya superioridad sobre cualquier otra modalidad del habla estriba en hallarse en la «gracia de la cháris» ${ }^{43}$, término griego que cabe traducir por belleza. Dado que en Grecia, como Heidegger resalta en otros contextos ${ }^{44}$, la belleza se identifica con el ser en cuanto tal, la pretensión del decir poético griego de apuntar a él nombrando a los dioses equivale al intento de enfatizar la belleza de todo aquello que es: del mismo modo que -según plantea en la conferencia sobre el origen de la obra de arte- el poema «logra que el ente brille y resuene» 45 haciendo notar el fondo de abertura habitualmente velado en su presencia, el mýthos pone de manifiesto la belleza de las cosas iluminando el ocultarse tras ellas de los dioses, que constituyen la esfera de lo bello por excelencia. Lo cual indica, por lo demás, que la experiencia griega del ser como belleza se asienta justamente sobre ese emerger de las cosas a partir de un fondo de oscuridad -la no-presencia del dios- que invariablemente se hurta en su aparición46. En otras palabras: en Grecia cada cosa es bella porque alberga un fondo indescifrable que la torna esencialmente opaca e impenetrable al tiempo que la dota de una particular consistencia. Pues por causa de esa opacidad, las cosas no sólo resultan en última instancia inapresables, sino que tampoco consienten su reducción a nada que no sea ellas mismas ni su intercambio por ninguna otra.

De tal consistencia o impenetrabilidad de las cosas da cuenta asimismo la tesis heideggeriana de la coincidencia griega entre el ser y el aparecer dentro de un límite, de manera que «allí donde falta la delimitación, nada puede llegar a presencia como lo que es» ${ }^{47}$. El comparecer de toda cosa exige en Grecia la adquisición de una delimitación que le proporcione su forma o figura específica y no pensable al modo de una delimitación arbitraria, accidental o advenida, ya que se trata de la delimitación que la cosa ostenta de suyo y determinante de su aparición en cuanto esta cosa concreta y no otra distinta. Pero esta noción de límite no se restringe a la del trazado o contorno que algo muestra. Antes bien, con ella se mienta la distancia, intervalo o "Entre" que la propia cosa es en su desplegarse entre la ocultación de la que surge y la ocultación a la que habrá de retornar con su término o desaparición. Por eso, Heidegger comenta que las cosas vienen a presencia en Grecia en el límite o Entre de una doble ausencia ${ }^{48}$. Y subrayando la remisión de este concepto ontológico del límite a la ocultación, señala que sólo la sustracción del fondo de abertura inherente a la patencia del ente permite que ésta suceda como delimitación ${ }^{49}$. Si a ello se añade que es la

\footnotetext{
43 Ibid., p. 115.

44 Cfr., entre otros lugares, Heidegger, M., «“Andenken”» y, especialmente, «Hölderlins Erde und Himmel», ambos en Erläuterungen zu Hölderlins Dichtung, op. cit., pp. 134 y 161-62.

45 Heidegger, M., «Der Ursprung des Kunstwerkes», en Holzwege, Frankfurt am Main, Vittorio Klostermann, 2003, p. 60.

46 Para la conexión existente en Grecia entre la belleza, los dioses y su consustancial sustraerse, cfr. Heidegger, M., «"Wie wenn am Feiertage..."», en Erläuterungen zu Hölderlins Dichtung, op. cit., p. 54 y Martínez Marzoa, F., El decir griego, Madrid, A. Machado, 2006, pp. 26-27 y 38-39.

47 Heidegger, M., Parmenides, op. cit., p. 121; cfr. también «Der Spruch des Anaximander», en Holzwege, op. cit., p. 368.

48 Cfr. Heidegger, M., «Der Spruch des Anaximander», en Holzwege, op. cit., pp. 361 y 368.

49 Cfr. Heidegger, M., «Die Herkunft der Kunst und die Bestimmung des Denkens», en Denkerfahrungen, Frankfurt am Main, Vittorio Klostermann, 1983, p. 148.
} 
mirada de la diosa Atenea - descrita como la diosa "que medita sobre el límite"- la que posibilita el surgimiento de las cosas dentro del límite que les corresponde 50 , tal delimitación se revela igualmente tributaria del ámbito de lo divino: en su inalienable asociación al límite, la presencia griega del ente depende de la no-presencia de los dioses que concede ese mismo límite.

Acabamos de comprobar cómo la visión heideggeriana del significado de los dioses griegos carece de toda connotación religiosa o teológica. Reforzando esta idea, Heidegger advierte que entre los griegos no hubo religión alguna ni cabe hablar tampoco, en consecuencia, de una teología griega51: la relación de los griegos con sus dioses excluye la calificación de fe o creencia ${ }^{52}$ en la medida en que únicamente su desaparición transformará el vínculo con la divinidad en vivencia religiosa ${ }^{53}$ y provocará el nacimiento de la teología 54 . En abierto rechazo de toda mirada retrospectiva desde el horizonte del cristianismo, el relato poético griego sobre los dioses trasluce para Heidegger un sentido netamente ontológico. Tan netamente ontológico que, a su juicio, es en él y no en otro lugar donde por primera vez acontece una alusión a lo ontológico en su distancia frente a lo óntico: en virtud del mencionado solapamiento en Grecia entre el aparecer de algo y su ser-dicho, el mýthos se define como palabra inicial del ser porque su nominación de los dioses representa el primer emerger del ser en su diferencia e intrínseca ligazón al ente 55.

\section{El tiempo de los dioses huidos: nombrar lo sagrado}

La nominación de los dioses propia del mýthos griego atestigua una determinada experiencia del ser según la cual el aparecer de todo ente envuelve un fondo de oscuridad tan consustancial a su presencia que sin él no acaecería presencia alguna. Si en oposición a Grecia, pero a la vez en rigurosa conexión con ella, Heidegger asigna al poetizar de Hölderlin la fundación de un nuevo tiempo histórico caracterizado como «el tiempo de los

\footnotetext{
50 Cfr. ibid., pp. 138-39.

51 Así, a propósito de su interpretación de los fragmentos de Heráclito, Heidegger apela a la necesidad de mantener el pensar inicial lejos de toda exégesis teológica, ya que «los dioses y lo divino del mundo griego no se prestan a la constitución de teología alguna, ni tan siquiera si se toma este rótulo en sentido muy amplio y no se identifica solamente con la explicación y sistematización racional del contenido doctrinal de una "religión" dada». Y a este respecto añade, con el fin de negar la existencia en Grecia del fenómeno religioso y, con él, de toda teología: «No hay en absoluto una "religión" griega. La palabra religio y el asunto al cual alude son esencialmente de carácter romano. Porque no hay ninguna "religión" griega, tampoco hay ninguna "teología" griega.» (Heraklit, op. cit., pp. 13-14). Sobre esto mismo se insiste en Hölderlins Hymne "Andenken", op. cit., p. 133

52 Cfr. Heidegger, M., Heraklit, op. cit., p. 15.

53 A este respecto señalará Heidegger: «La desdivinización (Entgötterung) es el estado de indecisión respecto a dios y los dioses. El cristianismo es precisamente quien más ha contribuido a este acontecimiento. Pero, lejos de excluir la religiosidad, la desdivinización es más bien la responsable de que la relación con los dioses se transforme en vivencia religiosa. Cuando se ha llegado a este punto, los dioses han huido.» («Die Zeit des Weltbildes», en Holzwege, op. cit., p. 76).

54 Cfr. Heidegger, M., Hölderlins Hymne “Andenken”, op. cit., pp. 132-33.

55 Cfr. Heidegger, M., Parmenides, op. cit., p. 104.
} 
dioses huidos y el dios que viene» ${ }^{56}$, parece lícito admitir que tal referencia a los dioses se hallará sujeta en su oposición al significado ontológico vigente para éstos en Grecia. La nueva abertura de la totalidad del ente que instaura la poesía de Hölderlin supondrá por ello una manera diferente de percibir el ser de las cosas que cobrará expresión poética en la nominación de la ausencia en ellas de los antiguos dioses griegos.

Para entender en qué consiste esta nueva concepción del ente, es necesario recordar que aquello a lo que Heidegger llama metafísica -el acontecimiento unitario que comporta el desenvolvimiento de la historia de Occidente- tiene su origen en la propia pretensión griega de apuntar al ser vehiculada en el mýthos por la nominación de los dioses y también definitoria de la forma de discurso que posteriormente recibiría el rótulo de filosofía: dado que ese trasfondo de abertura rehúye por principio todo intento de objetivación o aprehensión en conceptos, el propósito griego de hacerlo relevante no podía sino conducir a su pérdida o liquidación. A raíz de ésta, la presencia de las cosas, experimentada en Grecia como el abrirse a partir de un fondo de oscuridad insuperable en su rehusarse, quedará convertida en mera presencia sin fondo o pura actualidad. En su articulación metafísica, las cosas han dejado de ser opacas, consistentes o bellas en su impenetrabilidad para devenir objetos plenamente presentables en la representación del sujeto. Con la moderna restricción del ente a lo apto de ser sometido a explicación físico-matemática, todo ser-oculto se verá relegado a la condición de simple residuo, bien potencialmente explicable en un futuro más o menos lejano, bien descartado como superfluo en la realidad de la cosa allí donde se intuye inexplicable 57 . Transformadas en productos del cálculo planificado y por entero accesibles y disponibles a la voluntad de manipulación, el imperio de la técnica, fruto de la consumación de la metafísica, llevará a las cosas a aparecer en calidad de meras existencias (Bestand) íntegramente restituibles, intercambiables y suprimibles ${ }^{58}$. Y es que esa pérdida de consistencia del ente irá aparejada a la disolución de la noción griega del ser como límite en su esencial ensamblaje con la ocultación y no-presencia de los dioses: frente a la imposibilidad griega de que algo se exhiba sin la delimitación que de suyo lo conforma, el representar moderno no reconoce en el ente límite alguno ${ }^{59}$, de manera que, en ausencia de tal delimitación interna, cualquier cosa debe poder asociarse con y transmutarse en cualquier otra ${ }^{60}$. Éste es el vuelco en la manifestación del ente que Heidegger lee en la huida de los dioses poetizada por Hölderlin: el que, por obra de su inicial nominación en Grecia, cancela en las cosas el trasfondo de ocultación encarnado por lo divino y las reduce a lo puramente presentable y carente de límites.

En diferentes contextos, Heidegger describe este proceso en términos de un aplanamiento o nivelación, de una desaparición o caída del "pliegue" (Zwiefalt) de ser y ente ocurrida en los comienzos del pensar occidental pero inadvertida para éste61. En otros casos

56 Heidegger, M., «Hölderlin und das Wesen der Dichtung», en Erläuterungen zu Hölderlins Dichtung, op. cit., p. 47.

57 Cfr. Heidegger, M., Parmenides, op. cit., pp. 92-93.

58 Cfr. Heidegger, M., «Hölderlins Erde und Himmel», en Erläuterungen zu Hölderlins Dichtung, op. cit., p. 178.

59 Cfr. Heidegger, M., Beiträge zur Philosophie. Vom Ereignis, op. cit., p. 136.

60 Cfr. ibid., p. 132.

61 Cfr. Heidegger, M., «Moira», en Vorträge und Aufsätze, Stuttgart, Neske, 2000, pp. 232-33. 
habla de la caída del pliegue que configura el ser mismo ${ }^{62}$. Lejos de tratarse de una imprecisión conceptual, la ambivalencia u oscilación que aquí se observa en la utilización de la noción de ser -que el pliegue o hiato que se da entre ser y ente se predique a un tiempo del ser en cuanto tal- se revela índice de la complejidad que en sí misma entraña la cuestión ontológica. Pues eso que Heidegger denomina el pliegue del ser aspira a dar cuenta de la duplicidad o doblez que encierra el hecho de que "ser" signifique la presencia de esta y aquella cosa -el ser de esta y aquella cosa-, pero también, simultáneamente, el trasfondo de abertura oculto dejado atrás en su aparición y tan sólo patente en su retirada. En las ocasiones en las que Heidegger recalca la diferencia entre el ente y su ser -por ejemplo, al declarar que el «desocultamiento de lo ente, la claridad que le ha sido concedida, oscurece la luz del ser»63-, la palabra "ser" remite a esa dimensión de no-presencia encubierta en la presencia de la cosa y cuyo sustraerse permite su mostración. Sin embargo, la mencionada duplicidad del ser no tolera su identificación con uno solo de los lados de ese proceso unitario de desvelamiento y retracción: el ser posee la condición de un pliegue o doblez por consistir en una suerte de movimiento de diferenciación que, dando lugar a esas dos vertientes -el mostrarse del ente y el ocultarse que lo hace posible-, a la vez las reúne y entrelaza como momentos de un único movimiento. La diferencia del ser con respecto al ente coincide así con la diferencia que anida en el interior del propio ser -lo que Heidegger llama el ser mismo- concebido como pliegue o doblez entre el aparecer y el rehusarse inmanentes al haber de las cosas. En definitiva, el ser en cuanto tal se despliega en la unidad diferenciada de ser y ente en la medida en que la comparecencia de aquello que es-el ente- comporta invariablemente el sustraerse de ese mismo ser64.

Este carácter doble del ser justifica igualmente la paradójica afirmación heideggeriana de que la desaparición no percibida del pliegue del ser -la reducción del doblez entre desvelamiento y retracción del fondo de abertura a "mera presencia" sin fondo ni ocultaciónimplica a un tiempo el también inadvertido despliegue del pliegue del ser. Dado que la metafísica nada sabe de esa abertura oculta y además erige tal no-saber en principio explicativo de toda realidad 65 , la pérdida o caída del pliegue del ser, expresión idéntica a la más frecuente del olvido del ser, designa la doble ocultación que supone el encubrimiento de la ocultación imperante en toda presencia y que se plasma en la ausencia de reconocimiento de la diferencia entre ser y ente. Pero esta pérdida equivale asimismo al despliegue del pliegue del ser por la razón de que nada distinto al juego de mostración y retirada, de simultánea abertura y cierre aludido por dicho pliegue inaugura la metafísica y rige su desenvolvimiento histórico: el encubrimiento u obliteración de esa dimensión de no-presencia, resultante del intento griego de tematizarla, instaura como tal el horizonte dentro del cual las cosas se tornan susceptibles de plena presentación. Surgida tras el final de Grecia y asentada en la modernidad por medio de su conversión en objeto, la comprensión metafísica del ente como pura presencia o actualidad se constituye entonces en el terreno en el que ese fondo de abertura oculto alcanza a salir a la luz, si bien del único modo en que le es dado

62 Cfr. ibid., p. 244.

63 Heidegger, M., «Der Spruch des Anaximander», en Holzwege, op. cit., p. 337.

64 Cfr. Zarader, M., Heidegger et les paroles de l'origine, París, Vrin, 1990, pp. 137-42 y Martínez Marzoa, F., Heidegger y su tiempo, Madrid, Akal, 1999, pp. 14-15.

65 Cfr. Heidegger, M., Parmenides, op. cit., p. 167. 
hacerlo. Pues tratándose de aquello que sólo se exhibe en su escapar a toda mirada objetivante, su comparecencia no podrá cifrarse más que en la de su propia retracción o denegación. En este particular dinamismo reside el acaecer del pliegue del ser, desconocido e inaccesible para la metafísica: bajo la forma de su ausencia, el ser se despliega en la emergencia de la concepción metafísica del ente que lo oculta.

A pesar de que los griegos habitaron en la experiencia del pliegue del ser -y así lo atestigua la lengua griega, según Heidegger, en la ambigüedad de palabras como eón, alétheia, phýsis o lógos-, jamás llegaron a nombrarlo en cuanto tal pliegue ni tampoco a pensarlo66. Por este motivo, Heidegger plantea que una primera aparición del pliegue de ser y ente empieza a prepararse allí donde se inicia el acabamiento de la metafísica ${ }^{67}$. A tenor de la correspondencia de ese período crepuscular con el nacimiento del idealismo alemán y de la metafísica de Hegel, Heidegger sostiene que la preparación de tal aparecer incipiente del pliegue del ser acontece en la poesía de Hölderlin: gracias a su confrontación con la filosofía de su tiempo y a su extensa dedicación al estudio de las obras de Homero, Píndaro y Sófocles, su decir poético no se dejará ya circunscribir al ámbito de la metafísica por articularse sobre la base del reconocimiento de que la moderna presencia de las cosas reposa sobre la pérdida de la experiencia griega del ser68. El poetizar de Hölderlin en torno a la huida de los antiguos dioses evidencia así un primer avistamiento no sólo del olvido o desaparición del pliegue del ser, sino también de su despliegue, hasta ese momento inobservado, en el devenir histórico de Occidente: para Heidegger, la ausencia de los dioses cantada por el poeta haría patente el sustraerse del doblez del ser que subyace a la desaparición de la belleza y divinidad de las cosas en Grecia y fundamenta la percepción moderna de la inconsistencia del ente. De ahí que, a partir de su descubrimiento de la poesía de Hölderlin, de todo punto decisivo en su comprensión de la metafísica y de la historia del ser69, escriba: «El "a-teísmo", correctamente entendido como la falta de dioses (Götter-losigkeit), es el olvido del ser que, desde el ocaso de Grecia, domina la historia de Occidente en tanto rasgo fundamental de esta misma historia occidental» 70 . Semejante identificación entre la falta de dioses y el olvido del ser corrobora el carácter ontológico conferido por Heidegger a la huida de los dioses poetizada por Hölderlin: como reverso de la singular presencia de los dioses en Grecia, su ausencia indica el encubrimiento de la dimensión oculta que provoca la pérdida de belleza y consistencia de las cosas característica del olvido metafísico del ser.

Ahora bien, si la modernidad se define para Hölderlin por la huida de los dioses, el propósito de su labor poética no podrá ya radicar en su nominación. Siguiendo el dictum hölderliniano según el cual, a causa de la distancia irreductible que separa a los modernos del mundo griego, «no nos es lícito en absoluto tener algo igual con ellos» 71 , Heidegger subra-

66 Cfr. Heidegger, M., «Moira», en Vorträge und Aufsätze, op. cit., pp. 232-33.

67 Cfr. Heidegger, M., «Überwindung der Metaphysik», en Vorträge und Aufsätze, op. cit., p. 74.

68 Sobre esta idea insiste Heidegger en Hölderlins Hymne "Der Ister", op. cit., pp. 20, 30, 57, 66, y también en Über den Anfang, Frankfurt am Main, Vittorio Klostermann, 2005, p. 156.

69 Según Heidegger, la posibilidad de contemplar la metafísica como el acontecimiento unitario que tiene su origen en Grecia y determina el curso histórico de Occidente -posibilidad que en el marco de los Beiträge será designada como el "otro inicio"- habría sido ya "decidida" a través de la palabra de Hölderlin. Cfr. Heidegger, M., Über den Anfang, op. cit., pp. 150 y 156.

70 Heidegger, M., Parmenides, op. cit., p. 166.

71 Hölderlin, F., Ensayos, op. cit., p. 126. 
ya que el camino del poeta a Grecia se halla por entero al servicio del retorno a lo propio o natal para su apropiación y reconquista: sólo este viaje de ida y vuelta nos permitirá "llegara-ser-en-casa" en el constitutivo "no-ser-en-casa" 72 de la condición moderna, vinculada a un origen tan irrecuperable como inasimilable en su retirada. Por ello, frente al relato poético griego sobre los dioses, Heidegger defenderá que lo poetizado por Hölderlin se muestra en su obra bajo la denominación de "lo sagrado" (das Heilige $)^{73}$. En vez de aludir a la esfera de lo divino, con este término se apunta a aquello que, quedando por encima de dioses y hombres, determina sus respectivas esencias al establecer tanto su diferencia como su recíproca dependencia 74 . Fórmulas como die Natur, la "intimidad" (Innigkeit) o "lo más alto" (das Höchste) apelan igualmente a eso mismo que designa "lo sagrado", carente ya de todo nombre en los poemas más tardíos de Hölderlin y únicamente mencionado de forma indirecta $^{75}$. En todas esas expresiones Heidegger localiza un decir poético del ser ${ }^{76}$. Sin embargo, la propia ambivalencia que, según el análisis realizado anteriormente, se contiene en la palabra "ser" marcará la diferencia entre el decir poético griego y el de Hölderlin: así como el mýthos griego remite al ser a través de la figura de los dioses en referencia al fondo de ocultación obliterado en la presencia moderna del ente, el poetizar de Hölderlin no dice ya en lo sagrado ese fondo de abertura, sino el pliegue del ser en su despliegue histórico. En su visión de la modernidad como la época en la que Grecia y sus dioses comparecen en su puro sustraerse, lo sagrado nombra el pliegue o quicio entre el hurtarse del origen y su velada mostración en aquello que su propia retirada despliega; o, lo que es lo mismo, el pliegue por el cual el doblez del ser se da a ver en su rehusarse en la manifestación moderna del ente que deriva de su ausencia. En este sentido, Heidegger declarará que lo sagrado se halla por encima de divinos y mortales porque con él se mienta el "Entre" (Zwischen) o espacio intermedio originario que reúne en su nítida separación a los dioses, las figuras del ocultarse del ser, y a los hombres, que personifican el dominio del ente. Dado que ese Entre trasluce asimismo la distancia que distingue y entrelaza el devenir histórico de Occidente con el sustraerse de Grecia, en él se encuentran tanto el poeta como el semidiós, su reflejo poético. Gracias a esa posición intersticial, el semidiós poetizado por Hölderlin, en su representación paradigmática en la figura de Dionisos, «lleva la huella de los dioses huidos a aquellos que no tienen dioses» 77 . Pero su importancia estriba, ante todo, en que la interrogación poética

\footnotetext{
72 Cfr. Heidegger, M., Hölderlins Hymne “Der Ister”, op. cit., p. 171.

73 Cfr., entre otros lugares, Heidegger, M., Hölderlins Hymne "Der Ister", op. cit., p. 173 у "“Andenken”», en Erläuterungen zu Hölderlins Dichtung, op. cit., p. 103.

74 Cfr., Heidegger, M., Hölderlins Hymne “Der Ister”, op. cit., pp. 173 y 194, y «“Andenken”», en Erläuterungen zu Hölderlins Dichtung, op. cit., p. 104.

75 Cfr. Heidegger, M., Hölderlins Hymne "Der Ister”, p. 24; Hölderlins Hymnen "Germanien” und "Der Rhein”, op. cit., p. 250; Hölderlins Hymne “Andenken”, op. cit., pp. 134-35; y Über den Anfang, op. cit., p. 157.

76 A este respecto, la equivalencia establecida por Heidegger entre lo sagrado y el ser en la poesía de Hölderlin se hace especialmente patente en el curso de 1942 Hölderlins Hymne "Der Ister", en el que lo poetizado o aquello que esencialmente saca a la luz el poetizar (das Zu-Dichtende) se identifica expresamente tanto con lo sagrado como con el ser (cfr. op. cit., pp. 150 y 194).

77 Heidegger, M., Hölderlins Hymnen "Germanien" und "Der Rhein", op. cit., p. 188. Cfr. también «Wozu Dichters?», en Holzwege, op. cit., p. 271.
} 
de Hölderlin por la esencia del semidiós crea la separación "dadora de medida"78 que, abriendo una fractura entre dioses y hombres, se adentra por vez primera en la diferencia como tal79, esto es, en la diferencia entre ser y ente. Por eso el semidiós hölderliniano encarnará para Heidegger el Entre o pliegue del ser: al tiempo que delimita con claridad la distancia entre divinos y mortales, evidencia su mutua relación. Manteniendo unidas en su diferencia sus respectivas esferas, el semidiós ilumina el doblez del pliegue único que ser y ente conforman 80 .

En cuanto encarnación del pliegue del ser, el semidiós se erige en vehículo del problemático poetizar lo sagrado que Heidegger lee en Hölderlin81. Así se explica su anotación de que lo sagrado y el ser «nombran lo mismo, pero no son lo mismo»82. Puesto que ambos «dan noticia de aquello que impera y acontece antes de los dioses y los hombres» ${ }^{83} \mathrm{y}$, por tanto, del pliegue que traza la distinción entre unos y otros, nombran lo mismo. Pero no pueden ser lo mismo si, en virtud del abismo que separa al poetizar del pensar ${ }^{84}$, es el pensador quien pretende decir en conceptos el doblez del ser a partir de aquella experiencia de la huida de los dioses que, en continuidad con el mýthos griego, lleva al poeta a instaurar en lo sagrado el nombre poético de ese doblez en su despliegue histórico ${ }^{85}$. Más allá de que la equivalencia destacada entre el ser y lo sagrado denote la subordinación del significado de esta noción al sentido ontológico de lo divino acuñado por el relato poético griego, Heidegger negará literalmente la legitimidad de una interpretación de corte religioso o teológico de lo sagrado en el marco de la poesía de Hölderlin ${ }^{86}$. Si además se toma en consideración que, a su entender, esta expresión tan sólo sería una más de las diversas fórmulas -junto a die Natur, la "intimidad", "lo más alto"... - utilizadas por el poeta para señalar la dualidad que se alberga en el ser, cualquier exégesis de esta índole parece quedar de todo punto excluida. En lo que sigue trataremos de dilucidar si tal exclusión se deja extender al discurso sobre el "último dios" de los Beiträge zur Philosophie, cuya críptica redacción se ha situado bajo la influencia directa del diálogo de Heidegger con Hölderlin ${ }^{87}$.

78 Cfr. Heidegger, M., Hölderlins Hymnen “Germanien” und “Der Rhein”, op. cit., p. 226.

79 Cfr. ibid., p. 167. Cfr. asimismo «“Andenken”», en Erläuterungen zu Hölderlins Dichtung, op. cit., p. 105.

80 Cfr. Heidegger, M., Hölderlins Hymnen “Germanien” und “Der Rhein”, op. cit., p. 259 y ss.

81 Se trata de un poetizar problemático porque, como hemos estudiado en otra parte, Hölderlin debe enfrentarse a la tarea de sacar a la luz ese pliegue del ser haciendo a la vez justicia a su denegarse a ser-dicho. Por ello, Heidegger vinculará el decir poético de Hölderlin a un silencio que, lejos de cifrarse en el mero callar, consistirá en la operación de expresar poéticamente el ser pero sin decirlo propiamente, para así resguardar su carácter indecible. A este respecto, cfr. Martínez Matías, P., «Hölderlin y lo no-dicho: sobre la cuestión del silencio en la interpretación de Martin Heidegger de su poesía», Diánoia, 69, 2012, pp. 31-69.

82 Heidegger, M., Über den Anfang, op. cit., p. 157 (cursiva nuestra).

83 Ibid.

84 Cfr. Heidegger, M., «Nachwort zu "Was ist Metaphysik”», en Wegmarken, op. cit., p. 312.

85 Cfr. Allemann, B., Hölderlin und Heidegger, Freiburg, Atlantis, 1954, pp. 120-21.

86 Cfr. Heidegger, M., Hölderlins Hymne “Andenken”, op. cit., p. 132.

87 Cfr. Pöggeler, O., «Die engen Schränken unserer noch kinderähnlichen Kultur», en Jamme, C. y Pöggeler, O., Jenseits des Idealismus. Hölderlins letzte Homburger Jahre (1804-1806), Bonn, Bouvier, 1988, pp. 27-28. Sobre la importancia de Hölderlin en la emergencia de la figura del "último 


\section{El último dios: la asunción de la huida de los dioses}

Al margen de la trascendencia que, en contadas ocasiones, los Beiträge atribuyen a la obra de Hölderlin en el "pensar de la historia del ser" que aspiran a inaugurar, su influjo en la elaboración de este texto resulta indiscutible por varias razones. Tanto a lo largo de su extensa articulación como en la parte dedicada al último dios se apela de forma recurrente a la cuestión de la huida de los dioses. Por otra parte, Heidegger vuelve a plantear aquí, y en explícita referencia a la palabra de Hölderlin, «que nombra de nuevo a los dioses y al hombre» 88 , una asimilación del ser al Entre como espacio entre unos y otros, en cuya abertura tendría lugar su recíproco salir al encuentro y el reconocimiento de su mutua pertenencia ${ }^{89}$. Sobre esta misma idea se abunda en el conjunto de manuscritos de 1938 pertenecientes a la órbita de los Beiträge y editados con el título de Besinnung, en concreto en un largo capítulo sobre los dioses donde se aborda asimismo el problema del último dios ${ }^{90}$. En él se aclara que la nominación de los dioses a la que acude el pensar de la historia del ser carece por completo del propósito de introducir nuevos dioses, de instituir una nueva religión o de fundar alguna suerte de fe sin iglesia ni culto ${ }^{91}$. Antes bien, lo que con ella se intenta es abrir un ámbito de interrogación sobre la esencia de la divinidad (Gottschaft) cuyo objetivo residiría en retrotraerla a sus fundamentos. Desde un primer momento, Heidegger resalta el carácter ontológico de tal interrogación al conectarla con la necesidad de emplazar la pregunta por el ser en el terreno de la distinción entre el ser y el ente, de tal modo que así, este preguntar «piensa con el ser aquello que da una referencia primera y esencial a la nominación de los dioses» ${ }^{92}$. La relación establecida entre la nominación de los dioses y el ser en su diferencia con respecto al ente sugiere que, conforme a lo desarrollado posteriormente en el curso de 1942/43, también en este contexto los dioses apuntan a la dimensión de ocultación imperante en la experiencia griega de la presencia. Tal hipótesis vendría a ratificarse en el punto en que los Beiträge, en obvia alusión a Grecia, indican que la naturaleza fue una vez «el sitio para el instante de la llegada y de la morada de los dioses, cuando aún reposaba como phýsis en el acontecer esencial (Wesung) del propio ser» ${ }^{93}$. Pues en el concepto de phýsis Heidegger detecta uno de los términos que revelan el habitar griego en el pliegue del ser: con él se mienta el emerger o brotar desde la ocultación y llamado en sí mismo a ocultarse que en Grecia caracteriza el venir-a-presencia de las $\operatorname{cosas}^{94}$, y cuyo encubrimiento el mýthos hace patente nombrando a los dioses.

De acuerdo con esta idea, la fundamentación de la esencia de la divinidad por la que Heidegger apuesta en Besinnung se traduce en la intención de arrojar luz tanto sobre el valor

dios" de los Beiträge ha insistido igualmente J.-F. Coutine, si bien para plantear la existencia en este texto de una suerte de "teología postmetafísica" mencionada anteriormente (Cfr. («Les traces et le passage du Dieu dans les Beiträge zur Philosophie de Martin Heidegger», op. cit., pp. 533 y ss.).

88 Heidegger, M., Beiträge zur Philosophie. Vom Ereignis, op. cit., p. 423.

89 Cfr. ibid., pp. 423, 428 y 476.

90 Cfr. Heidegger, M., Besinnung, Frankfurt am Main, Vittorio Klostermann, pp. 227-56.

91 Cfr. ibid., p. 249.

92 Ibid., p. 231.

93 Heidegger, M., Beiträge zur Philosophie. Vom Ereignis, op. cit., p. 277.

${ }^{94}$ Cfr., entre otros lugares, Heidegger, M., «Alétheia», en Vorträge und Aufsätze, op. cit., pp. 262-64. 
puramente ontológico de los dioses en Grecia como sobre los efectos de su huida en el seno de la metafisica. Tal fundamentación supondría entonces un retorno a su esencia inicial que, lejos de concernir a algo pasado, topa con «la esencia de la verdad del ser, en cuyo acontecer esencial se encuentra en lo venidero el último dios» ${ }^{95}$. Para entender a qué pueda remitir este último dios, es preciso tener en cuenta la mencionada disociación entre la introducción de nuevos dioses y su nominación en el pensar de la historia del ser, que impide de entrada concebirlo como un "nuevo dios" cuya venida fuera anunciada por Heidegger. En función de lo señalado en los Beiträge, la condición venidera o futura que se le asigna obedece, por un lado, a la ubicación de la aparición de ese último dios en el "otro inicio". Pero, asimismo, al hecho de que el desvelamiento del pliegue del ser en su acaecer histórico -lo que aquí se formula como la "verdad del ser"-, comprendido además en cuanto tal ser como rehusamiento (Verweigerung), se califique a su vez de venidero o futuro 96 : de la misma manera que los dioses en Grecia reflejaban lo oculto e indisponible en la presencia del ente, el último dios se vincula con insistencia a ese rehusarse o denegarse del ser, hasta el punto de presentarse como la «figura suprema del rehusamiento» ${ }^{97}$ por tratarse de aquel que en sí mismo se rehúsa ${ }^{98}$. La inteligibilidad de la figura del último dios girará, por tanto, en torno al significado de la naturaleza venidera de tal rehusamiento del ser en su relación con el otro inicio.

Tanto los Beiträge como los restantes escritos privados de esta época pretenden preparar el tránsito desde el "primer inicio" -la historia de la metafísica desde su comienzo en Grecia- hacia ese "otro inicio" en el que se inscribe el último dios. Sin embargo, tal y como se advirtió al comienzo de este trabajo, no cabe interpretar ese otro inicio al modo de la inauguración de un nuevo período histórico que dejara tras de sí a la metafísica. Antes bien, Heidegger lo solapa estrictamente con un retroceso hacia el primer inicio encaminado a someterlo a una repetición o reiteración originaria99: en lugar de contemplarlo como un período pretérito y acabado, la novedad de esta repetición -y, por ende, del otro inicio en cuanto tal- radicaría en poner de manifiesto en ese primer inicio, a través del diálogo con sus pensadores ${ }^{100}$, el olvido del ser antes encubierto que lo determina y sobre el cual se erige nuestra propia actualidad histórica ${ }^{101}$. En este sentido, el otro inicio no consistiría más que en el reconocimiento de la metafísica como historia del despliegue del ser102. $\mathrm{O}$, lo que es

\footnotetext{
95 Heidegger, M., Besinnung, op. cit., p. 243 (cursiva nuestra).

96 Cfr. Heidegger, M., Beiträge zur Philosophie. Vom Ereignis, op. cit., p. 406.

97 Ibid., p. 416.

98 Cfr. ibid., p. 412.

99 Cfr. ibid., pp. 57-58.

100 Cfr. ibid., pp. $185-87$ y 169.

101 De ahí que Heidegger conciba ese diálogo también en términos de una confrontación (Auseinandersetzung) y advierta de que el retroceso (Rückgang) hacia el primer inicio para su reiteración originaria no implica una mera vuelta al pasado para su reproducción. Antes bien, ese diálogo retrospectivo se establece sobre la base del distanciamiento que permite leer en la metafísica lo que necesariamente permaneció oculto para ella. En palabras de Heidegger: «El salto hacia el otro inicio es el retroceso hacia el primero y viceversa. Pero el retroceso al primer inicio (la "re-petición" (Wieder-holung)) no es ningún trasladarse al pasado (...). El retroceso al primer inicio es más bien y precisamente alejamiento de él, el instalarse en aquella toma de distancia que es necesaria para tener experiencia de lo que comenzó en aquel inicio y como aquel inicio.» (ibid., p. 185).

102 Cfr. ibid., p. 171.
} 
lo mismo, en la instauración de la perspectiva que por vez primera daría a ver, en el desenvolvimiento de la historia de Occidente, el oculto acontecer del ser en su denegación o rehusamiento como forma misma de su despliegue o donación ${ }^{103}$. Pero puesto que esa confrontación con la historia del pensamiento occidental constituye la tarea aún no asumida ni llevada a cabo por la filosofía, la reflexión de los Beiträge se arroga una función meramente "preparatoria"104 del tránsito hacia el otro inicio, que, consecuentemente, y al igual que el último dios ligado a él, habrá de tener en lo porvenir su espacio de comparecencia.

A ello debe añadirse que los Beiträge parten de una premisa ya citada en ocasiones precedentes: a causa de ese rehusamiento del ser, la metafísica permanece necesariamente ajena a toda noción acerca del trasfondo encubierto que marca su devenir. Por este motivo, llegar a poner de relieve ese trasfondo exigirá, en primera instancia, despertar de algún modo una experiencia del mismo, esto es, llevarlo a "resonar" - la primera fuga que articula los Beiträge lleva precisamente por título "la resonancia" (der Anklang)- como primer paso para el ulterior descubrimiento de que ese sustrato hasta entonces velado configura inadvertidamente la irrupción y desarrollo de la metafísica. Esta labor inicial que acometen los Beiträge se cifra en la tarea de hacer notar el llamado "abandono de los entes por el ser" o "abandono del ser" (Seinsverlassenheit). Heidegger comenta que lo característico de su culminación, que acaece en la modernidad bajo el rostro de la llamada "maquinación" (Machenschaft) - término que preludia lo que más tarde se definirá como la esencia de la técnica o Gestell-, anida no sólo en la negativa moderna a aceptar la existencia de nada que se oculte, sino en que «el ocultarse como tal no tiene de ningún modo cabida como poder determinante» 105 . De ello se deduce que tal abandono del ser nombra en esta etapa la obliteración del fondo de oscuridad que provoca la transformación de la presencia griega en "mera presencia" y que, a partir de la modernidad, cimenta la idea del ente como objeto plenamente producible y manipulable106. Pero Heidegger considera, además, que la máxima negación y encubrimiento del abandono del ser se produce a través del cristianismo y de sus descendientes secularizados ${ }^{107}$. Entre los efectos de la huida de los dioses examinados en Besinnung se analiza la denominada "divinización" (Vergötterung), concepto que, según se desprende de este texto, designa el proceso por el cual el aplanamiento del pliegue del ser genera la ontificación de los dioses griegos y su conversión en causa suprema del ente. En esta transformación, Heidegger concede un papel crucial al dios cristiano por comportar su naturaleza creadora la explicación de toda cosa -desprovista en su quedar explicada de toda dimensión de oscuridad-como ens creatum, es decir, como algo hecho por otro ente108. De esta manera siembra el germen de la "desdivinización" (Entgötterung)109 del mundo, iniciada en la modernidad cuando el proceder explicativo subyacente a la búsqueda de causas se traslada al sujeto y origina la comprensión del ente en calidad de artefacto o producto del

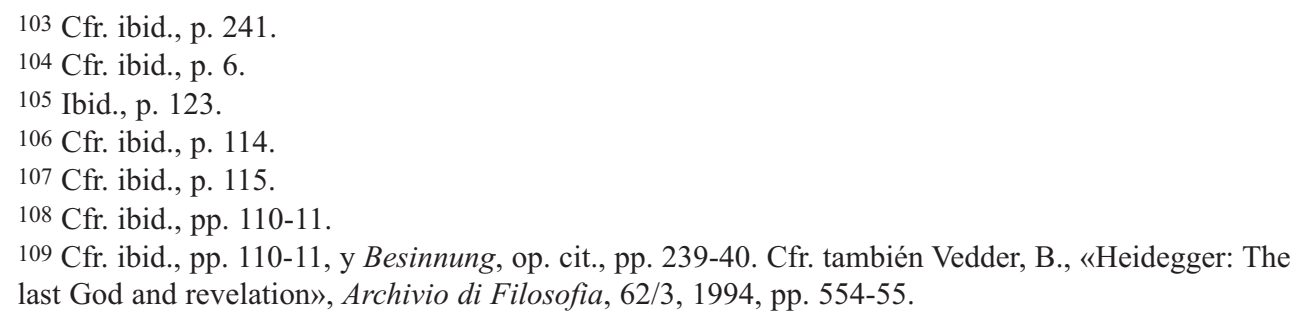


hacer humano. De ahí que la divinización y la desdivinización derivada de ella -y, en correspondencia con ambas, no sólo toda forma de teísmo, sino también de ateísmo110, idénticamente tributaria en su negación de la ontificación del ser habilitada por la huida de los dioses- constituyan para Heidegger plasmaciones históricas del olvido del ser de decisiva importancia en la historia de Occidente111: al ocupar el espacio vacío de los antiguos dioses griegos, el nacimiento del dios cristiano y la desdivinización del mundo a la que aboca encubren su ausencia e impiden el reconocimiento de su huida.

Se explica así que, en esta fase preparatoria del otro inicio, los Beiträge también formulen la voluntad de sacar a la luz el rehusamiento del ser en términos de la urgencia de hacer resonar, por primera vez, «la lejana proximidad de la huida de los dioses» ${ }^{112}$. Con ello dan a entender que -en concordancia con el significado que se le confiere en la interpretación de la poesía de Hölderlin- dicha huida sería en cuanto tal asimilable al propio rehusamiento del ser que impulsa el despliegue de la metafísica. Y puesto que la revelación venidera de tal rehusamiento coincide con la aparición del último dios, en función de lo expuesto cabe conjeturar que, lejos de anunciar la emergencia de una nueva forma de divinidad, Heidegger piensa bajo esta figura tanto la consolidación de la experiencia de la huida de los dioses poetizada por Hölderlin como la definitiva y aún por llegar asunción de su pérdida. Si ya en los primeros parágrafos de los Beiträge se sentencia que «la huida de los dioses tiene que ser experimentada y resistida» 113 , tal asunción se identificaría con la disposición a soportar la ausencia de toda forma de divinidad una vez el dios cristiano se descubre, en tanto vehículo de la ocultación de la huida de los dioses griegos, manifestación de la donación del ser en su rehusamiento. Pues así como el desvelamiento de ese rehusamiento o denegación del ser no consiste en forzar al ser a salir de su retirada, sino, por el contrario, en mantenerla con firmeza haciendo justicia a su consustancial sustraerse y al carácter inaprehensible e inobjetivable que le es inherente ${ }^{114}$, la figura del último dios apelaría igualmente a la necesidad de aceptar que el único modo de relación venidera con lo divino estribará en aprender a sobrellevar su ausencia.

Esta interpretación justifica la tajante afirmación de Besinnung según la cual la fundamentación de la esencia de la divinidad perseguida por el pensar de la historia del ser, y destinada a encontrar en lo venidero al último dios, sólo puede suceder sobre la base de la «superación de cualquier deseo de "religión"» 115 e incluso prohíbe «todo corto desear cuyas vías apunten todavía en la dirección de la "religión" y la "religiosidad"»116. O que, en la misma línea, se indique que el encuentro entre hombres y dioses que habrá de tener lugar a partir del despliegue esencial de la verdad del ser «ya no puede ser más "religión"»117. Dada la mencionada inexistencia en Grecia del fenómeno religioso, así como la dependencia de su surgimiento del de la propia divinidad cristiana que brota de la huida de los antiguos dio-

110 Cfr. Heidegger, M., Beiträge zur Philosophie. Vom Ereignis, op. cit., p. 411, y Besinnung, op. cit., p. 249.

111 Cfr. Heidegger, M., Besinnung, op. cit., p. 240.

112 Heidegger, M., Beiträge zur Philosophie. Vom Ereignis, op. cit., p. 113.

113 Ibid., p. 27.

114 Cfr. Zarader, M., Heidegger et les paroles de l'origine, op. cit., p. 17.

115 Heidegger, M., Besinnung, op. cit., p. 243.

116 Ibid.

117 Ibid. 
ses griegos, la inviabilidad de cualquier forma de religión destacada por Heidegger vincularía al último dios con la desaparición no restituible de toda presencia de lo divino en el otro inicio salvo la que implicaría el hacerse cargo de su pérdida.

El discurso heideggeriano sobre el último dios permanece circunscrito al ámbito de los escritos privados de finales de los años treinta. Sin embargo, la cuestión de los dioses seguirá vigente en posteriores interpretaciones de la poesía de Hölderlin y cobrará un renovado protagonismo en el momento en que el pliegue del ser pase a expresarse con la noción de la "cuadratura" (Geviert), configurada por el juego unitario de referencias recíprocas de cuatro elementos: el cielo, la tierra, los mortales y los divinos. En esa cuadratura o dimensión la divinidad comparece de nuevo como aquello que se hurta y es iluminado por el poeta en su intrínseco e irreductible ocultarse. Midiéndose con ese ocultarse de la divinidad en los aspectos visibles del cielo, el poeta toma la medida del habitar de los mortales sobre la tierra. Por ello, según Heidegger, Hölderlin establece la medida de nuestro presente, construido sobre el sustraerse de tal ocultación de lo divino, en la ausencia de toda medida que lo conduce a la «extraña sobremedida de un frenético medir y calcular» ${ }^{118}$. En el denegarse de todo límite dado de antemano en el ente más allá de los que impone el calcular humano119 se hallaría el signo de esa ausencia de medida que, desde la pérdida de los dioses griegos y el encubrimiento de la abertura oculta del ser que delata, se constituye paradójicamente en la medida de nuestro tiempo.

\section{Referencias bibliográficas}

Alleman, B.: Hölderlin und Heidegger. Freiburg: Atlantis, 1954.

Caputo, J. D.: «Heidegger and theology». En: Guignon, C., The Cambridge Companion to Heidegger. Cambridge University Press, 1993, pp. 270-288.

Courtine, J.-F.: «Les traces et le passage du Dieu dans les Beiträge zur Philosophie de Martin Heidegger». Archivio di Filosofia, 62/3, 1994, pp. 519-538.

HeIDEGger, M.: Denkerfahrungen. Frankfurt am Main: Vittorio Klostermann, 1983.

HeIDEgGer, M.: Identidad y diferencia/Identität und Differenz. Barcelona: Anthropos, 1988. HeIDEGGer, M.: Hölderlins Hymne “Andenken”. Frankfurt am Main: Vittorio Klostermann, 1992.

Heidegger, M.: Parmenides. Frankfurt am Main, Vittorio Klostermann, 1992.

HeIDeGger, M.: Hölderlins Hymne "Der Ister". Frankfurt am Main: Vittorio Klostermann, 1993.

Heidegger, M.: Heraklit. Frankfurt am Main: Vittorio Klostermann, 1994.

Heidegger, M.: Phänomenologische Interpretationen zu Aristoteles. Einführung in die Phänomenologische Forschung. Frankfurt am Main: Vittorio Klostermann, 1994.

Heidegger, M.: Beiträge zur Philosophie. Vom Ereignis. Frankfurt am Main: Vittorio Klostermann, 1994.

HeIDegger, M.: Erläuterungen zu Hölderlins Dichtung. Frankfurt am Main: Vittorio Klostermann, 1996.

118 Heidegger, M., «“... dichterisch wohnet der Mensch...”», en Vorträge und Aufsätze, op. cit., p. 197. 119 Cfr. Heidegger, M., Parmenides, op. cit., p. 226. 
Heidegger, M.: Was heißt Denken? Tübingen: Niemeyer, 1997.

HeIdegger, M.: Besinnung. Frankfurt am Main: Vittorio Klostermann, 1997.

HeIDEgGer, M.: Einführung in die Metaphysik. Tübingen: Niemeyer, 1998.

HeIDegGer, M.: Hölderlins Hymnen "Germanien” und "Der Rhein”. Frankfurt am Main:

Vittorio Klostermann, 1999.

Heidegger, M.: Vorträge und Aufsätze. Stuttgart: Neske, 2000.

HeidegGer, M.: Holzwege. Frankfurt am Main: Vittorio Klostermann, 2003.

HeIDEGger, M.: Wegmarken. Frankfurt am Main: Vittorio Klostermann, 2004.

HeIdegger, M.: Über den Anfang. Frankfurt am Main: Vittorio Klostermann, 2005.

Hölderlin, F.: Ensayos, trad. de Martínez Marzoa, F. Madrid: Hiperión, 1990.

Hermann, F.-W. v.: Wege ins Ereignis. Zu Heideggers "Beiträge zur Philosophie". Frankfurt am Main: Vittorio Klostermann, 1994.

JunG, M.: «Heidegger und die Theologie. Konstellationen zwischen Vereinnahmung und Distanz». En: Thomä, D., Heidegger Handbuch. Stuttgart: Metzler, 2003, pp. 474-481.

KIENZleR, K.: «"Der kommende Gott" - Die Elegie "Brot und Wein” bei Hölderlin». Archivio di Filosofia, 62/3, 1994, pp. 305-317.

LEYTE, A.: Heidegger. Madrid: Alianza, 2005.

Martínez MarzoA, F.: «A propósito de los "Beiträge zur Philosophie" de Heidegger». Daimon, 2, 1990, pp. 241-246.

Martínez MarzoA, F.: Heidegger y su tiempo. Madrid: Akal, 1999.

Martínez MarzoA, F.: El decir griego. Madrid: A. Machado, 2006.

MARTíneZ MATíAs, P.: «Hölderlin y lo no-dicho: sobre la cuestión del silencio en la interpretación de Martin Heidegger de su poesía». Diánoia, 69, 2012, pp. 31-69.

Отто, W. F.: Los dioses de Grecia, trad. de Berge, R. y Murguía, A. Madrid: Siruela, 2003. PöGGELER, O.: «Die engen Schränken unserer noch kinderähnlichen Kultur». En Jamme, C. y Pöggeler, O., Jenseits des Idealismus. Hölderlins letzte Homburger Jahre (18041806). Bonn: Bouvier, 1988, pp. 9-52.

ThurnhER, R.: «Gott und Ereignis - Heideggers Gegenparadigma zu Onto-Theologie». Heidegger Studien, 8, 1992, pp. 81-102.

Vedder, B.: «Heidegger: The last God and revelation». Archivio di Filosofia, 62/3, 1994, pp. 553-564.

ZARADER, M.: Heidegger et les paroles de l'origine. París: Vrin, 1990.

Paloma Martínez Matías

Departamento de Historia de la Filosofía

Universidad Complutense de Madrid

pmartinezmatias@filos.ucm.es 